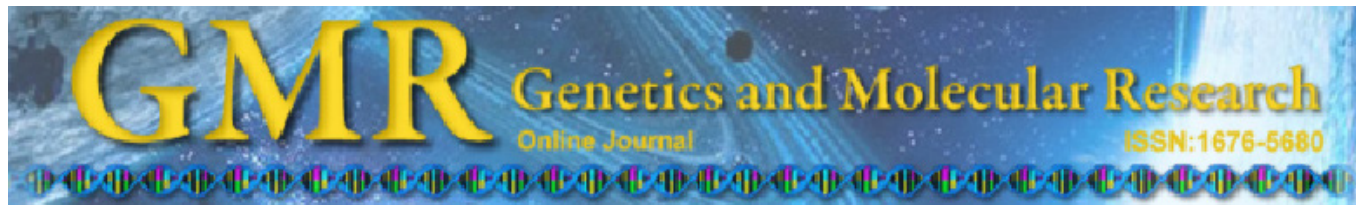

Methodology

\title{
Characterization of a rice germin-like protein gene promoter
}

\author{
T. Mahmood ${ }^{1}$, T. Yasmin ${ }^{3}$, M.I. Haque ${ }^{4}$ and S.M.S. Naqvi ${ }^{2}$ \\ ${ }^{1}$ Department of Plant Sciences, Quaid-i-Azam University, Islamabad, Pakistan \\ ${ }^{2}$ Department of Biochemistry, PMAS Arid Agriculture University Rawalpindi, \\ Rawalpindi, Pakistan \\ ${ }^{3}$ Department of Biosciences, COMSATS Institute of Information Technology, \\ Islamabad, Pakistan \\ ${ }^{4}$ Department of Plant Pathology, \\ PMAS Arid Agriculture University Rawalpindi, Rawalpindi, Pakistan
}

Corresponding author: S.M.S. Naqvi

E-mail: saqlan@uaar.edu.pk

Genet. Mol. Res. 12 (1): 360-369 (2013)

Received April 12, 2012

Accepted August 7, 2012

Published February 7, 2013

DOI http://dx.doi.org/10.4238/2013.February.7.6

ABSTRACT. Germin and germin-like proteins (GLPs) are water-
soluble extracellular proteins that are expressed in response to specific
environmental and developmental signals. Although some enzymatic
activities have also been associated with germin/GLPs, their role in
overall metabolism is not fully understood. However, insight into their
function may be gained by analysis of their promoter. The present study
was designed to analyze the functional importance of a root-expressed
Oryza sativa GLP gene promoter (OsRGLP2). One of the most striking
properties of the OsRGLP2 promoter, which we report for the first time,
is its wound-inducible activity. In fully grown plants, tissue-specific
OsRGLP2 promoter activity was observed in the inner and outer phloem
of the mid rib, at the petiole stem junction, in cortical cells adjacent to the
phloem, in the epidermal layer cells and epidermal hairs of the stem, in
young xylem cells, and in petal veins, whereas in sepals it was diffused 
and found only in the younger parts. No activity was observed in the mid rib, blade, or apex of mature and young leaves. The OsRGLP2 promoter was also found to be salt and dehydration responsive, whereas temperature had almost no effect on its activity. Of note, 6-benzylaminopurine showed some effect on promoter activity, whereas indole-3-acetic acid had no effect. Microscopic analysis showed sharp glucuronidase gene expression in leaf veins under salt stress, which was diffused in all other treatments. The results of this study indicate that the OsRGLP2 is a robust promoter capable of driving expression of downstream genes under certain stress conditions, including wounding, salt and dehydration.

Key words: Germin-like protein gene; Wounding; Promoter; Oryza sativa; Tobacco transformation; GUS expression

\section{INTRODUCTION}

Germin is a protein that was initially observed in association with wheat seed germination, from which it was named "germin". It is a water-soluble glycoprotein with oxalate oxidase (OXO) activity, and forms an oligomer that is highly resistant to proteases and to dissociation by various denaturing agents such as heat, sodium dodecyl sulfate and extreme $\mathrm{pH}$. Proteins with sequence identity to germins have been identified from wheat and other plant species, and are known as germin-like proteins (GLPs). A potentially important function of germin and GLPs is their involvement in plant defense. A recent report of this important property was published by Manosalva et al. (2009), in which RNA interference-based silencing of an Oryza sativa GLP (OsGLP) gene family member (on chromosome 8) was shown to be involved in resistance against two diseases, rice blast and sheath blight. A more specific example regarding the efficacy of GLP promoters in defense against pathogen has been reported by Himmelbach et al. (2010). They analyzed a group of 8 paralogous promoters of the barley GLP subfamily 4 and confirmed a high transcript expression level upon pathogen attack. The possible involvement of GLPs in tolerance to osmotic stress is in agreement with the demonstration that germins and GLPs are part of a superfamily of proteins, including seed storage globulins as well as a sucrose binding protein, which are potentially involved in cellular water homeostasis (Braun et al., 1996).

Germins and GLPs have been suggested to be stress-responsive gene products. For example, accumulation of germin mRNA is upregulated during the growth of germinating barley seedlings in the presence of $\mathrm{NaCl}$ (Hurkman and Tanaka, 1996), while Berna and Bernier (1999) reported a lack of any change in either germin abundance or in OXO in the presence of $\mathrm{NaCl}$ in 2-day-old wheat seedlings. Salt stress can also alter the localization of germins in plant tissues. The in situ RNA hybridization-based study by Caliskan (2009) revealed changes in the expression site of germin gene products. In water-grown embryos, germin was expressed in coleorhiza cells, whereas in salt-stressed embryos, germin mRNA accumulation was observed in coleoptile cells and not in the coleorhiza tissue.

Germin and GLP expression has been reported in a number of diverse situations in various plant species (Hurkman et al., 1991, 1994; Hurkman and Tanaka, 1996); however, characterization of upstream regions of GLP-coding genes is required. Mathieu et al. (2003) have reported the cloning of a 1520-bp Pinus caribaea germin1 (PcGER1) promoter region and the expression pattern of this promoter during the growth of tobacco bright yellow 2 
cells. PcGER1 promoter activity was observed in the presence of 2,4-dichlorophenoxyacetic acid (2,4-D) and 6-benzylaminopurine (BAP) at day 4, at the end of the exponential growth phase in which $70-75 \%$ cells have $2 \mathrm{C}$ DNA content. In addition, further analysis of promoter activity during the cell cycle in an aphidicolin-synchronized culture suggested that its expression is maximal in G1 cells.

Although the rice genome is much larger than that of Arabidopsis, the rice genome appears to have fewer GLP genes; hence, their characterization will present a simpler overall picture. In the present study, a 1107-bp fragment upstream of the O. sativa GLP gene promoter (OsRGLP2) was cloned and sequenced. Analysis through BLAST revealed three important findings. Firstly, this sequence has been duplicated almost 6 times in an approximately $30-\mathrm{kb}$ region of chromosome 8 . Secondly, these duplications contained 5 conserved regions, which were designated as CR1-CR5. Thirdly, it revealed a number of putative regulatory elements, including those responsible for light responsiveness, dehydration and dark-induced senescence, stresses (pathogen and salt), plant growth regulators, pollenspecific expression, and elements related to seed storage proteins (Mahmood et al., 2007). In order to obtain further insight into the conditions responsible for driving the function of this promoter region, this region was cloned upstream of the glucuronidase (GUS) gene into a pCAMBIA $1391 Z$ vector and transformed into Nicotiana tabaccum cv. Samsun. Resultant transgenic plants revealed interesting aspects of this putative promoter region.

\section{MATERIAL AND METHODS}

\section{Plant material}

Seeds of the relatively salt-tolerant rice cultivar $O$. sativa L. cv. Nona Bokra were obtained from the International Rice Research Institute in the Philippines. The rice seeds were grown under greenhouse conditions for extraction of genomic DNA to be used as a template for amplification of the promoter region of the OsRGLP2 homologue.

\section{OsRGLP2 promoter construct}

The promoter region (accession No. DQ414400) of the OsRGLP2 homologue from $O$. sativa L. cv. Nona Bokra was amplified, cloned, and sequenced (Mahmood et al., 2007). The 1107-bp promoter region was cloned into the SmaI site of a pCAMBIA $1391 Z$ vector (Hajdukiewicz et al., 1994) harboring a GUS gene reporter system, and was ultimately electroporated into Agrobacterium tumefaciens (EHA101) for subsequent plant transformation.

\section{Plant transformation and expression analysis}

The leaf disk method was used for tobacco transformation (Curtis et al., 1995). Transgenic plants were confirmed by PCR and GUS staining (Jefferson, 1989), then were transferred to pots and gradually acclimatized to the greenhouse conditions. Tissues were excised from greenhouse-maintained transgenic plants at an advanced vegetative stage and were stained and observed under a light microscope. 


\section{Wound-induced activity of the OsRGLP2 promoter}

Wound-induced activity of the OsRGLP2 promoter was observed in different tissues of transgenic plants, including leaves, petioles, petiole-stem junctions, stems, and roots. This property of wound induction was 1st observed accidently during handling of the transgenic plants with forceps and scissor while performing the GUS assay. Wound-induced activity of the OsRGLP2 promoter was monitored in petioles at 30, 60, and 120 min post-wounding. A negative control was also prepared by the same treatments to samples from PCR-negative plants.

\section{Effect of temperature, dehydration, salt, cytokinin, and auxin on promoter activity}

Different treatments were applied to the leaves of transgenic plants, including temperature variation $\left(28^{\circ}, 32^{\circ}, 36^{\circ}\right.$, and $\left.40^{\circ} \mathrm{C}\right)$, dehydration (at room temperature), salt stress $(0$, $25,50,75,150$, and $250 \mathrm{mM})$, BAP [a cytokinin $(0,2,4$, and $8 \mathrm{mg} / \mathrm{L})$ ], and indole- 3 -acetic acid [IAA, an auxin $(0,0.1,0.2$, and $0.4 \mathrm{mg} / \mathrm{L})]$ administered at $0,30,60$, and $120 \mathrm{~min}$. Leaves of equal sizes and ages from the same plant were collected for each analysis and the petiole was dipped in the respective treatment solution, with 3 replicates.

\section{Tissue-specific activity of the OsRGLP2 promoter}

Various plant tissues were stained for GUS activity, and tissue-specific localized expression of the OsRGLP2 promoter was observed and photographed with and without a microscope.

\section{RESULTS AND DISCUSSION}

\section{Wound-induced activity of the OsRGLP2 promoter}

GUS assays performed on transgenic tobacco plants expressing GUS under the control of OsRGLP2 revealed strikingly high expression at the sites of wounding (Figure 1). Magnified images (100X) showed high GUS expression on cut edges and in the veins of the stained leaf pieces (Figure 1). GUS expression was also observed at cut edges of the leaf petiole and mid-rib in response to wounding (Figure 2). Wound-induced OsRGLP2 promoter activity was also demonstrated by staining the petiole with GUS for different time intervals after cutting $(0,30,60$, and $120 \mathrm{~min})$. As shown in Figure 3, GUS expression increased at cut petiole edges over time (Figure 3).

It has been known for quite some time that several germins and GLPs act as OXOs (Neutelings et al., 1998) or superoxide dismutases (Carter and Thornburg, 2003; Christensen et al., 2004; Kukavica et al., 2005) and produce reactive oxygen species that provide protection against microbial infection (Hurkman and Tanaka, 1996; Carter and Thornburg, 2003). In a detailed study of the in planta role of OXO in Lolium perenne, Le Deunff et al. (2004) concluded that germin OXOs might be instrumental during critical events in the life of plants, such as cutting and senescence by initiating $\mathrm{H}_{2} \mathrm{O}_{2}$-mediated defenses against pathogens and foraging animals. Other mechanisms such as reinforcement of cell walls by GLPs have also been suggested (Lane, 1994; Christensen et al., 2000; Kim et al., 2004). 


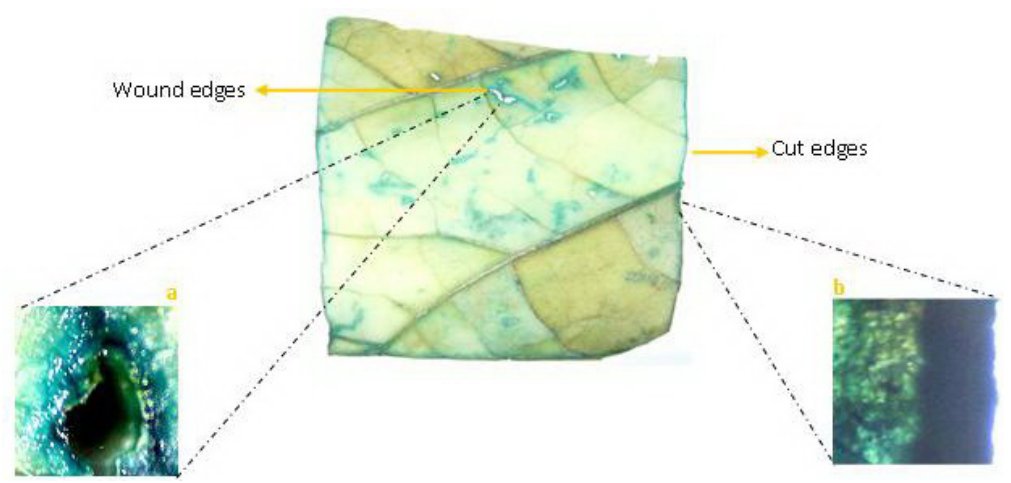

Figure 1. GUS staining of leaf tissues showing GUS expression at cut edges and at wounding sites (a. and b.). Magnification, 100X. The wound sites were a result of handling by forceps during handling.
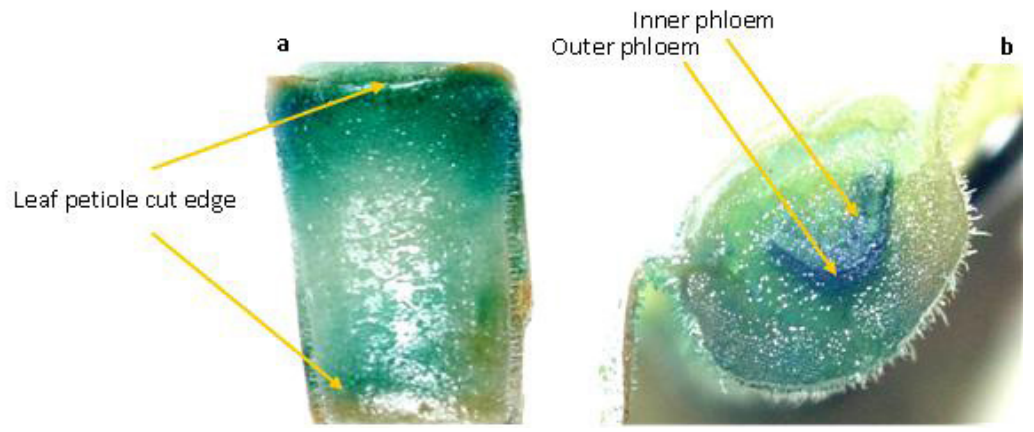

Figure 2. Tissue-specific expression in petiole and midrib cross section. a. Petiole. b. Midrib cross section.

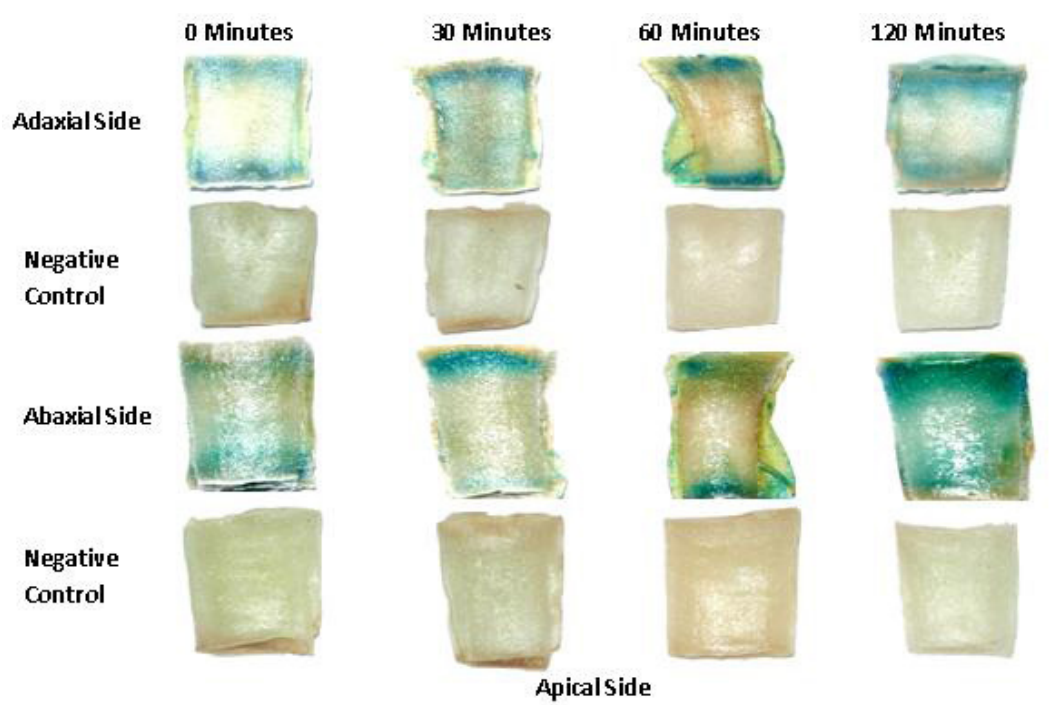

Figure 3. Analysis of wound-induced activity of the OsRGLP2 promoter at cut edges of leaf petiole with increasing time. 
The evidence of possible promoter induction by wounding in the present study may also strengthen the hypothesis that GLPs play an important role in generalized plant defense (Schafleitner and Wilhelm, 2002; Segarra et al., 2003). To the best of our knowledge, this is the 1 st report of wound inducibility of a GLP promoter. Our data build upon the results of previous reports that suggest a role of GLPs at the site of injury, as GLPs are widely implicated in microbial defense in various ways (Dunwel et al., 2008); hence, the possibility exists for a role of GLPs at the wound site to protect microbial entry (Naqvi et al., 2005). A striking observation was the induction of this promoter after wounding. The few reports available regarding GLP promoter analysis (Staiger et al., 1999; Carter and Thornburg, 2003) are silent on this aspect.

\section{Effect of temperature on OsRGLP2 promoter activity}

The effect of temperature was also monitored in leaves of transgenic tobacco plants at different temperatures $\left(28^{\circ}, 32^{\circ}, 36^{\circ}\right.$, and $40^{\circ} \mathrm{C}$ ) and under different time regimes (control, 30 , 60 , and $120 \mathrm{~min}$ ), which resulted in no visible effect on OsRGLP2 promoter activity. A previous study also indicated that GLP expression was not positively correlated with heat treatment in barley (Vallelian-Bindschedler et al., 1998).

\section{Effect of dehydration and salt stress on OsRGLP2 promoter activity}

Leaves of transformed plants were left at room temperature for $0,30,60$, and $120 \mathrm{~min}$ for dehydration followed by determination of GUS expression. GUS expression was upregulated overtime, thereby demonstrating the dehydration responsiveness of the OsRGLP2 promoter. Microscopic analysis revealed relatively diffused GUS expression in response to dehydration (Figure 4a). Dehydration is not a simple absence of water faced by plant cells during water shortages; rather, the plant cell cytoplasm becomes dense, which causes an increase in intracellular salt concentration. Therefore, the unavailability of water determines the induction of water stress as well as that of many salt-responsive gene products. Hurkman et al. (1994) and Hurkman and Tanaka (1996) were the 1st to report GLP induction in barley roots during salt stress. Earlier, Ramagopal (1987) in barley and Naqvi et al. (2009) in rice observed the induction of apparently similar proteins during salt stress by two-dimensional electrophoresis, although they did not characterize these proteins by sequencing. It has also been reported that salt stress can enhance wheat germin promoter activity in transgenic tobacco (Berna and Bernier, 1997, 1999). Similar results were obtained during this investigation when the OsRGLP2 promoter was analyzed under salt stress conditions, which was reasonable and strengthens the existing knowledge regarding the salt-induced expression of GLP gene products. In the current study, maximum GUS expression was observed after treatment with $75 \mathrm{mM} \mathrm{NaCl}$ for $30 \mathrm{~min}$. Magnified images (100X) showed high expression levels in veins and neighboring mesophyll cells (Figure 4b). Yin et al. (2009) identified 10 genes responsible for drought tolerance in rice, including one GLP, thus supporting our observation that GLPs may play a role during dehydration.

\section{Plant growth regulator-induced activity of the OsRGLP2 promoter}

The OsRGLP2 promoter region was reported to contain 3 copies of cytokinin-responsive ARR1 elements (Mahmood et al., 2007). To explore the induction of OsRGLP2 by 
cytokinins, BAP was used at concentrations of $0,2,4$, and $8 \mathrm{mg} / \mathrm{L}$ at different time intervals; however, no significant activity could be detected. ARR1 elements alone may therefore not be sufficient for cytokinin responsiveness. Different concentrations $(0,0.1,0.2$, and $0.4 \mathrm{mg} / \mathrm{L})$ of IAA were also used to analyze the effect of auxins on the OsRGLP2 promoter. Microscopic images (100X) showed diffused GUS expression (Figure 4c), although no auxin-responsive element was detectable by Signal Scan. Yin et al. (2009) showed that Arabidopsis GLP4, which is localized in the Golgi and able to specifically bind with auxins (IAA and 2,4-D), might play a role in regulating cell growth. In another more recent study, the effect of auxin on stimulating ethylene production and in regulating $P s$-GLP transcripts was investigated in plum fruit; auxins were found to have a role in the regulation of 2 GLP genes (Ps-GLP1 and $P_{S}$-GLP2) involved in the development and ripening of fruits (El-Sharkawy et al., 2010).

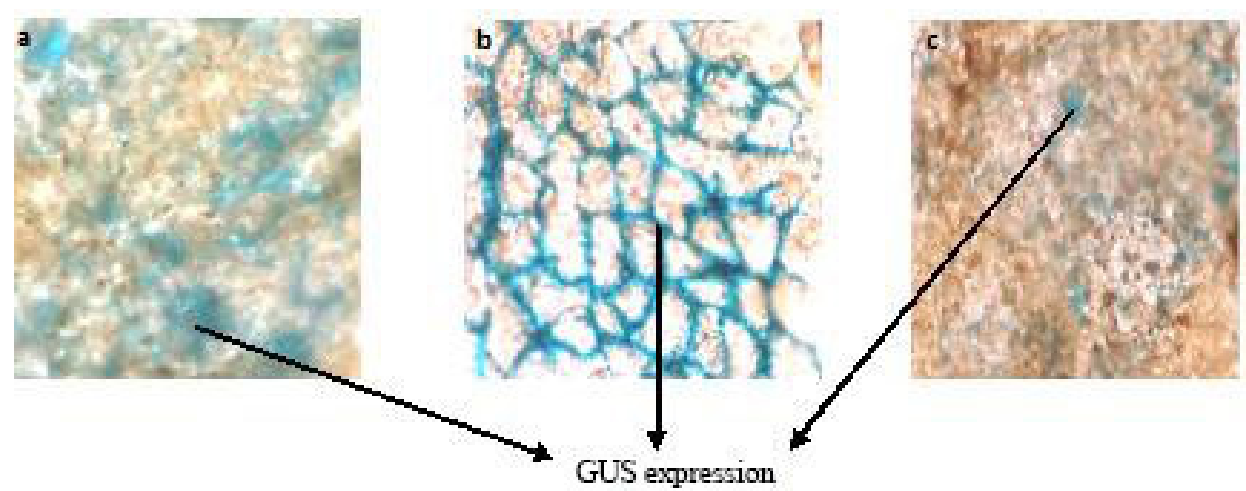

Figure 4. Microscopic analysis of the effects of a. dehydration after $120 \mathrm{~min}$, b. salt stress, c. IAA on OsRGLP2 promoter activity (magnification, 100X).

\section{Tissue-specific expression of the OsRGLP2 promoter}

Different tissues from transgenic plants (mature and young leaves, petioles, stem, roots, and flowers) were analyzed for tissue-specific expression of the OsRGLP2 promoter. No expression was observed in mature and young leaf apices, blades, and midribs. GUS expression was observed on cut edges of petioles and in vascular tissues of leaf midrib cross sections (Figure 2), whereas microscopic studies revealed GUS expression in inner and outer phloems of leaf midrib cross sections (Figure 5a). OsRGLP2 promoter activity was monitored in immature leaf stems at the petiole stem junction (Figure 5b), which on microscopic examination was observed to be present in phloem, cortical cells adjacent to phloem, epidermal layer cells, and in epidermal hair (Figure 5c). In flowers, GUS expression was observed in petals and in growing edges of sepals (Figure 5d). Microscopic images revealed clear GUS expression in petal veins, whereas sepals was diffused and observed only in growing parts (Figure 5e). Root cross sections indicated the presence of GUS expression in young xylem cells, phloem cells, and cortical cells adjacent to phloem (Figure 6).

Taken together, the present OsRGLP2 promoter analysis revealed interesting findings regarding the induction of one of the GLPs. The induction on wounding is an important feature of this promoter, which may be utilized in the preparation of economically important insect-resistant transgenic plants. One of the major impediments to the acceptability of geneti- 
cally modified organisms is the use of promoters of viral origin; therefore, the use of a strong promoter of plant origin such as that in the current report might lessen some concerns about genetically engineered crops.
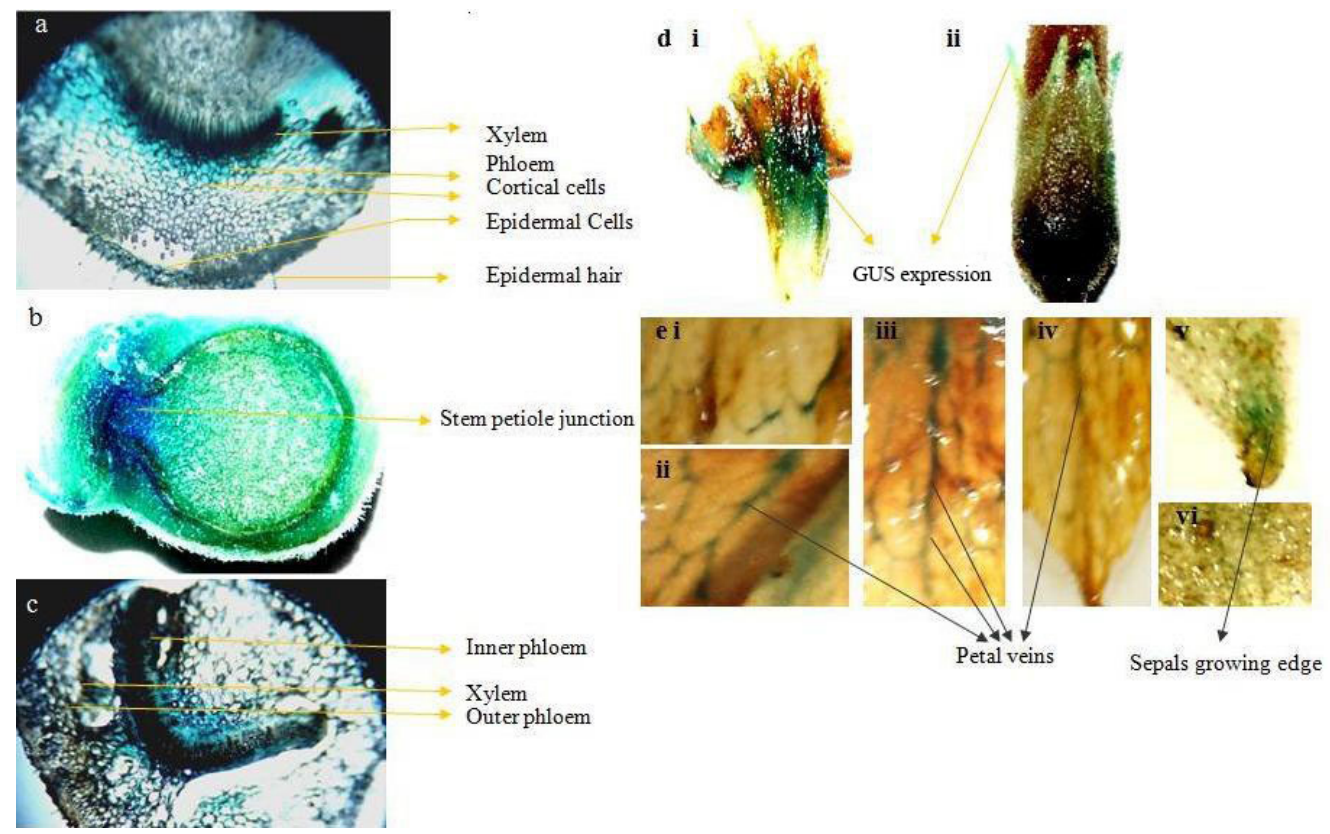

Figure 5. Microscopic analysis of different tissues of transgenic tobacco plants harboring the GUS gene under OsRGLP2 promoter (a) midrib cross section, (b) stem cross section showing the GUS expression in petiole stem junction, (c) stem cross section showing GUS expression in inner and out phloem, (d) GUS expression in (i) petal, (ii) sepals, and (e) diffused GUS expression in sepals (i to iv), and at growing edges in parts of petals (v to vi).

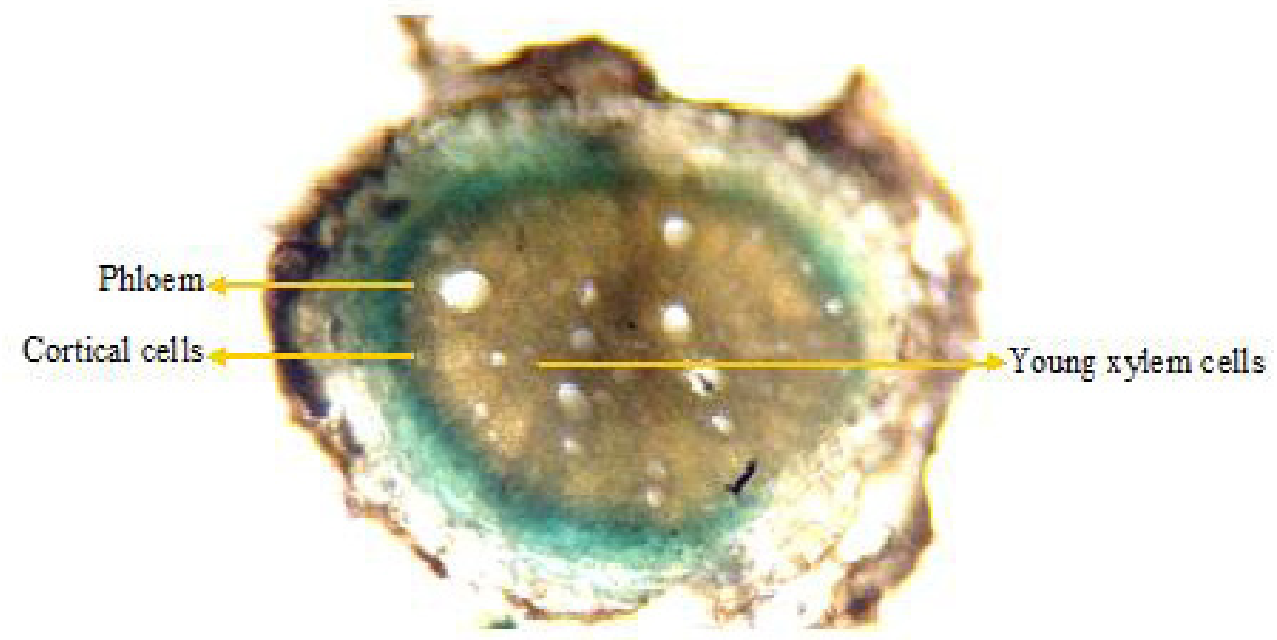

Figure 6. Microscopic image of transformed tobacco root cross section after GUS staining. 
This finding may further be supported by the evidence that in addition to wounding, the dehydration and salt-induced activities are also important characteristics of the OsRGLP2 promoter. In dehydration conditions, OsRGLP2 promoter activity increased over time, whereas salt stress at $75 \mathrm{mM}$ was observed to induce maximum OsRGLP2 promoter activity. Results from both dehydration and salt stress conditions further support previous reports suggesting that GLPs are stress-responsive gene products (Bohnert et al., 1988; Hurkman et al., 1994; Hurkman and Tanaka, 1996). Dehydration and salt-induced expression of the OsRGLP2 promoter, along with tissue-specific expression in phloem of stem and roots, might be used for engineering salt tolerance by expressing genes involved in salt transport (such as the $\mathrm{Na}^{+} / \mathrm{H}^{+}$ anti-porter) under this promoter (Qiu et al., 2002, 2004). It is also interesting and important to note that this promoter of monocot origin can function in a dicot plant. These features of the OsRGLP2 promoter indicate that it is a strong promoter that exhibits inducible properties in response to abiotic stresses in both mono- and dicotyledonous plants.

\section{ACKNOWLEDGMENTS}

The authors thank the International Rice Research Institute (IRRI) in the Philippines for providing Oryza sativa L. cv. Nona Bokra seeds. The pCAMBIA $1391 \mathrm{Z}$ vector was a gift from CAMBIA in Australia. Research partially supported by the Agriculture Linkage Program, Pakistan Agricultural Research Council (Grant \#01-03-01-19) to S.M.S. Naqvi.

\section{REFERENCES}

Berna A and Bernier F (1997). Regulated expression of a wheat germin gene in tobacco: oxalate oxidase activity and apoplastic localization of the heterologous protein. Plant Mol. Biol. 33: 417-429.

Berna A and Bernier F (1999). Regulation by biotic and abiotic stress of a wheat germin gene encoding oxalate oxidase, a $\mathrm{H}_{2} \mathrm{O}_{2}$-producing enzyme. Plant Mol. Biol. 39: 539-549.

Bohnert HJ, Ostrem JA, Cushman JC, Michalowski CB, et al. (1988). Mesembryanthemum crystallinum, a higher plant model for the study of environmentally induced changes in gene expression. Plant Mol. Biol. Rep. 6: 10-28.

Braun H, Czihal A, Shutov AD and Baumlein H (1996). A vicilin-like seed protein of cycads: similarity to sucrose-binding proteins. Plant Mol. Biol. 31: 35-44.

Caliskan M (2009). Salt stress causes a shift in the localization pattern of germin gene expression. Genet. Mol. Res. 8: $1250-1256$.

Carter C and Thornburg RW (2003). The nectary-specific pattern of expression of the tobacco Nectarin I promoter is regulated by multiple promoter elements. Plant Mol. Biol. 51: 451-457.

Christensen JH, Baucher M, Connell AO, van Montagu M, et al. (2000). Control of Lignin Biosynthesis. In: Molecular Biology of Woody Plants. (Jain SM, Minocha S, eds.). Vol. 1. Kluwer Academic Publishers, Dordrecht, 227-267.

Christensen AB, Thordal-Christensen H, Zimmermann G, Gjetting T, et al. (2004). The germinlike protein GLP4 exhibits superoxide dismutase activity and is an important component of quantitative resistance in wheat and barley. Mol. Plant Microbe Interact. 17: 109-117.

Curtis IS, Davey MR and Power JB (1995). Leaf disk transformation. Methods Mol. Biol. 44: 59-70.

Dunwell JM, Gibbings JG, Mahmood T and Naqvi SMS (2008). Germin and germin-like proteins: evolution, structure, and function. Crit. Rev. Plant Sci. 27: 342-375.

El-Sharkawy I, Mila I, Bouzayen M and Jayasankar S (2010). Regulation of two germin-like protein genes during plum fruit development. J. Exp. Bot. 61: 1761-1770.

Hajdukiewicz P, Svab Z and Maliga P (1994). The small, versatile pPZP family of Agrobacterium binary vectors for plant transformation. Plant Mol. Biol. 25: 989-994.

Himmelbach A, Liu L, Zierold U, Altschmied L, et al. (2010). Promoters of the barley germin-like GER4 gene cluster enable strong transgene expression in response to pathogen attack. Plant Cell 22: 937-952.

Hurkman WJ and Tanaka CK (1996). Effect of salt stress on germin gene expression in barley roots. Plant Physiol. 110: 
971-977.

Hurkman WJ, Tao HP and Tanaka CK (1991). Germin-like polypeptides increase in barley roots during salt stress. Plant Physiol. 97: 366-374.

Hurkman WJ, Lane BG and Tanaka CK (1994). Nucleotide sequence of a transcript encoding a germin-like protein that is present in salt-stressed barley (Hordeum vulgare L.) roots. Plant Physiol. 104: 803-804.

Jefferson RA (1989). The GUS reporter gene system. Nature 342: 837-838.

Kim HJ, Pesacreta TC and Triplett BA (2004). Cotton-fiber germin-like protein. II: Immunolocalization, purification, and functional analysis. Planta 218: 525-535.

Kukavica B, Vucinic Z and Vuletic M (2005). Superoxide dismutase, peroxidase, and germin-like protein activity in plasma membranes and apoplast of maize roots. Protoplasma 226: 191-197.

Lane BG (1994). Oxalate, germin, and the extracellular matrix of higher plants. FASEB J. 8: 294-301.

Le Deunff E, Davoine C, Le Dantec C, Billard JP, et al. (2004). Oxidative burst and expression of germin/oxo genes during wounding of ryegrass leaf blades: comparison with senescence of leaf sheaths. Plant J. 38: 421-431.

Mahmood T, Hyder MZ and Naqvi SM (2007). Cloning and sequence analysis of germin-like protein gene 2 promoter from Oryza sativa L. ssp. indica. DNA Seq. 18: 26-32.

Manosalva PM, Davidson RM, Liu B, Zhu X, et al. (2009). A germin-like protein gene family functions as a complex quantitative trait locus conferring broad-spectrum disease resistance in rice. Plant Physiol. 149: 286-296.

Mathieu M, Neutelings G, Hawkins S, Grenier E, et al. (2003). Cloning of a pine germin-like protein (GLP) gene promoter and analysis of its activity in transgenic tobacco Bright Yellow 2 cells. Physiol. Plant 117: 425-434.

Naqvi SM, Harper A, Carter C, Ren G, et al. (2005). Nectarin IV, a potent endoglucanase inhibitor secreted into the nectar of ornamental tobacco plants. Isolation, cloning, and characterization. Plant Physiol. 139: 1389-1400.

Naqvi SMS, Raza SQ, Hyder MZ, Ozalp CV, et al. (2009). Sub-cellular distribution of two salt-induced peptides in roots of Oryza sativa L. var Nonabokra. Afr. J. Biotechnol. 8: 4613-4617.

Neutelings G, Domon JM, Membre N, Bernier F, et al. (1998). Characterization of a germin-like protein gene expressed in somatic and zygotic embryos of pine (Pinus caribaea Morelet). Plant Mol. Biol. 38: 1179-1190.

Qiu QS, Guo Y, Dietrich MA, Schumaker KS, et al. (2002). Regulation of SOS1, a plasma membrane $\mathrm{Na}^{+} / \mathrm{H}^{+}$exchanger in Arabidopsis thaliana, by SOS2 and SOS3. Proc. Natl. Acad. Sci. U. S. A. 99: 8436-8441.

Qiu QS, Guo Y, Quintero FJ, Pardo JM, et al. (2004). Regulation of vacuolar $\mathrm{Na}^{+} / \mathrm{H}^{+}$exchange in Arabidopsis thaliana by the salt-overly-sensitive (SOS) pathway. J. Biol. Chem. 279: 207-215.

Ramagopal S (1987). Differential mRNA transcription during salinity stress in barley. Proc. Natl. Acad. Sci. U. S. A. 84: 94-98.

Schafleitner R and Wilhelm E (2002). Isolation of wound-responsive genes from chestnut (Castanea sativa) microstems by mRNA display and their differential expression upon wounding and infection with the chestnut blight fungus (Cryphonectria parasitica). J. Physiol. Mol. Plant Pathol. 61: 339-348.

Segarra CI, Casalongue CA, Pinedo ML, Ronchi VP, et al. (2003). A germin-like protein of wheat leaf apoplast inhibits serine proteases. J. Exp. Bot. 54: 1335-1341.

Staiger D, Apel K and Trepp G (1999). The Atger3 promoter confers circadian clock-regulated transcription with peak expression at the beginning of the night. Plant Mol. Biol. 40: 873-882.

Vallelian-Bindschedler L, Mosinger E, Metraux JP and Schweizer P (1998). Structure, expression and localization of a germin-like protein in barley (Hordeum vulgare L.) that is insolubilized in stressed leaves. Plant Mol. Biol. 37: 297-308.

Yin K, Han X, Xu Z and Xue H (2009). Arabidopsis GLP4 is localized to the Golgi and binds auxin in vitro. Acta Biochim. Biophys. Sin. 41: 478-487. 